Research Paper

\title{
The Use of Androgen Deprivation Therapy (ADT) and Chemotherapeutic Agents in New Zealand Men with Prostate Cancer
}

\author{
Ross Lawrenson $^{1}$, Zuzana Obertová1, Charis Brown¹, Peter Fong², Leanne Tyrie 3 , Nina Scott ${ }^{4}$, Michael \\ Holmes $^{5}$ \\ 1. Waikato Clinical School, University of Auckland, Hamilton, New Zealand \\ 2. Oncology Services, Auckland District Health Board, Auckland, New Zealand \\ 3. Radiation Oncology, Waikato Hospital, Hamilton, New Zealand \\ 4. Te Puna Oranga, Waikato District Health Board, Hamilton, New Zealand \\ 5. Urology Department, Waikato Hospital, Hamilton, New Zealand
}

$\triangle$ Corresponding author: Prof. Ross Lawrenson, Waikato Clinical School, Peter Rothwell Academic Centre, Private Bag 3200, Hamilton 3240, New Zealand. Tel.: +64 78398750 ext. 98170; Fax: +64 7839 8712; Email: ross.lawrenson@waikatodhb.health.nz

() Ivyspring International Publisher. This is an open-access article distributed under the terms of the Creative Commons License (http://creativecommons.org/ licenses/by-nc-nd/3.0/). Reproduction is permitted for personal, noncommercial use, provided that the article is in whole, unmodified, and properly cited.

Received: 2013.II.17; Accepted: 2014.01.18; Published: 2014.02.14

\begin{abstract}
Purpose: To assess the patterns of use of androgen deprivation therapy (ADT) and chemotherapeutic agents in New Zealand men with prostate cancer.

Methods: Men diagnosed with prostate cancer between 2006 and 201 I were identified from the New Zealand Cancer Registry. Through data linkage with the Pharmaceutical Collection and the National Minimum Dataset information on subsidised anti-androgens, luteinising hormone-releasing hormone (LHRH) analogues, chemotherapeutic agents, and orchidectomy was retrieved. The frequency of ADT and chemotherapy use in the first year post-diagnosis was assessed by patients' age, ethnicity, and extent of disease at diagnosis.

Results: The study population included 15,947 men diagnosed with prostate cancer, of whom 4978 (3I\%) were prescribed ADT or chemotherapeutic agents. ADT was dispensed for $72 \%$ of men with metastatic disease. Only $24(0.2 \%)$ men received chemotherapeutic agents. Men with advanced (regional or metastatic) disease older than 70 were more likely to receive anti-androgens only and to be treated with orchidectomy compared with younger men. Māori and Pacific men (compared with non-Māori/non-Pacific men) were more likely to receive pharmacologic ADT, and Māori men were also more likely to be treated with orchidectomy.

Conclusions: It was expected that all men diagnosed with metastatic prostate cancer should be using ADT in the first year post-diagnosis. However, for more than one-fourth of men neither anti-androgens nor LHRH analogues were dispensed within this period. Chemotherapeutic agents were used very rarely, so it seems that both pharmacologic ADT and chemotherapy is under-utilised in New Zealand patients with advanced prostate cancer.
\end{abstract}

Key words: anti-androgens, LHRH analogues, chemotherapy, orchidectomy, prostate cancer

\section{Introduction}

Prostate cancer is the most common cancer diagnosed in New Zealand (NZ) males and the third most common cause of male cancer deaths. ${ }^{1}$ Generally prostate cancer is a slow growing cancer with relatively good prognosis, with $80 \%$ of patients with localised disease being still alive at 15 years. ${ }^{2}$ Around 
$70 \%$ of men in NZ are identified with low-grade prostate cancer with a good prognosis. ${ }^{3}$ Unfortunately, some men present with advanced disease and their first symptoms may be due to metastases. The stage and grade of cancer will obviously influence treatment options, as will the presence of various co-morbidities. ${ }^{4}$ Men with metastatic prostate cancer may be offered pharmacologic androgen deprivation therapy (ADT), specific chemotherapeutic medication or be treated with orchidectomy. ${ }^{5}$

In New Zealand, Māori men are less likely to be diagnosed with prostate cancer but have a $70 \%$ increased risk of dying compared with non-Māori men. ${ }^{6}$ Moreover, Māori men diagnosed with non-localised prostate cancer have a threefold risk of dying from the disease compared with non-Māori men. ${ }^{7}$ Variation in treatment may be one of the reasons for the observed survival disparities. In the UK, increased use of ADT has been linked to the trend of decreasing mortality. ${ }^{8}$ It is possible that variation in the use of ADT also contributes to the survival differences between Māori and non-Māori men with non-localised prostate cancer. However, little information is available on the use of ADT and chemotherapeutic agents in prostate cancer patients in New Zealand.

The aim of this study was to ascertain the patterns of dispensing ADT, including anti-androgens and luteinising hormone-releasing hormone (LHRH) analogues, and chemotherapeutic agents in New Zealand men within the first year after prostate cancer diagnosis. We also explored the effect of age, ethnicity, year of diagnosis and orchidectomy on pharmacologic ADT use.

\section{Methods}

This nationwide audit of androgen deprivation therapy and chemotherapy treatment for prostate cancer was undertaken in New Zealand, a nation of 4.5 million people with a universally subsidised health system that includes free public hospital and pharmaceutical care.

We identified a cohort of men diagnosed with prostate cancer between 1 January 2006 and 31 December 2011 from the New Zealand Cancer Registry (NZCR, http://www.health.govt.nz/nz-health-statist ics/national-collections-and-surveys/collections/ne w-zealand-cancer-registry-nzcr), which collects data on all new cases of malignant cancers in NZ excluding squamous cell carcinoma and basal cell carcinoma of the skin. For each patient NZCR data included date of diagnosis, extent of disease at diagnosis, age at diagnosis, and ethnicity. The extent of cancer at diagnosis is coded in the NZCR as follows: B (localised), C (invasion of adjacent tissues or organs), $\mathrm{D}$ (invasion of regional lymph nodes), $\mathrm{E}$ (distant metastases), and $\mathrm{F}$ (unknown). For the purpose of our study, C and D extent were grouped under the category "regional spread". Only about one-quarter of prostate cancer cases have an extent at diagnosis listed in the NZCR, and the accuracy of the extent has not been assessed yet. Therefore, the extent of prostate cancer at diagnosis used in this study needs to be understood as that recorded in the NZCR, and may potentially differ from the actual extent at diagnosis.

Data for the cohort of men identified from the NZCR were linked to the Pharmaceutical Collection by a unique encrypted number derived from the National Health Index (NHI) number, which is unique for every public health system user in New Zealand. The Pharmaceutical Collection is an administrative claims database that contains information from pharmacists on dispensing subsidised medications. Once a funded prescription is dispensed in New Zealand the data are collected in a national repository and available for analysis. In addition to prescriber details, the medication name, strength, quantity and dosage are recorded.

For our study, data were extracted on androgen deprivation therapy, including anti-androgens (flutamide, bicalutamide, cyproterone) and LHRH analogues (goserelin, leuprorelin), and also on chemotherapeutic agents (doxorubicin, epirubicin, paclitaxel, mitozantrone, docetaxel). The information included chemical ID, indicating the primary active chemical ingredient, and the therapeutic group level 1-3 (more detail on http:/ / www.pharmac.health.nz/ tools-resources/pharmaceutical-schedule).

In addition, registration data were linked to the National Minimum Dataset (national collection of public and private hospital discharge information on inpatients and day patients) to identify men treated with orchidectomy.

Men with prostate cancer morphology not consistent with adenocarcinoma (67), men with unknown ethnicity (1478) and those diagnosed at death (374) were excluded from the analysis. In addition, 17 men were excluded because their domicile was listed as "overseas".

We examined the frequency of ADT and chemotherapy use in the first year after the initial diagnosis by patients' age ( $<60$ years, $60-69$ years, $70-79$ years, 80+ years), ethnicity (Māori, Pacific and non-Māori/non-Pacific), and extent of disease at diagnosis. Differences between distributions were tested using the $\chi^{2}$ or Fisher exact test (when sub-group sample sizes were small). Probability ( $\mathrm{p}$ ) values $<0.05$ were considered to be statistically significant. Multivariate logistic regression models were constructed to assess the likelihood of use of ADT for patients with advanced (regional spread and metastatic) prostate 
cancer, adjusting for age, ethnicity, year of diagnosis and orchidectomy.

\section{Results}

The final study population included 15,947 men diagnosed with prostate cancer in New Zealand in the six years between 2006 and 2011. Table 1 summarises the demographic information (age and ethnicity) by extent of prostate cancer at diagnosis. Most men were diagnosed between the ages of 60 and 79 years (68.2\%). There were 908 (5.7\%) Māori men, 445 (2.8\%) Pacific men, and 14,594 (91.5\%) non-Māori/ non-Pacific men in the sample. The proportion of Māori men in the 2006 Census total NZ male population of $50+$ years (since most prostate cancer cases occur in men aged $50+$ ) was $7 \%$, while Pacific males comprised 3\%, and non-Māori/non-Pacific men $90 \%$.

In total, $15.0 \%$ of men were recorded as having localised extent at diagnosis, $7.6 \%$ regional spread, $5.8 \%$ metastases, and $71.7 \%$ were recorded with unknown extent.

Androgen deprivation therapy (flutamide, bicalutamide, cyproterone, goserelin, leuprorelin) or chemotherapeutic agents (doxorubicin, epirubicin, paclitaxel, mitozantrone, docetaxel) were dispensed for 4978 (31.2\%) men in the first year following their initial diagnosis. Chemotherapeutic agents were dispensed only for 24 men $(0.2 \%)$. Most of the patients received doxorubicin (11), with docetaxel being the second most common agent used (5). Due to such a small sample size, patients with chemotherapy were not considered in the regression analysis.

Within the first year post-diagnosis, pharmacologic ADT was dispensed for 47 patients with localised prostate cancer at diagnosis $(1.9 \%$ of all men with localised disease recorded in the NZCR), 266 patients with regional spread $(22.1 \%)$ and 664 patients with distant metastases $(71.8 \%)$. Due to the small number and proportion of patients with localised disease who received ADT within one year post-diagnosis, further analysis focused on patients with regional and metastatic prostate cancer. Figures 1 and 2 show the frequency of types of pharmacologic ADT by age, ethnicity and extent of disease at diagnosis (regional spread, distant metastases, and all extent (including localised, regional, distant and unknown extent).

Table I. Demographic characteristics of men diagnosed with prostate cancer by extent of disease at diagnosis*.

\begin{tabular}{|c|c|c|c|c|c|}
\hline Extent at diagnosis & $\begin{array}{l}\text { Localised } \\
(\mathrm{N}=2385)\end{array}$ & $\begin{array}{l}\text { Regional spread } \\
(\mathrm{N}=1205)\end{array}$ & $\begin{array}{l}\text { Metastatic } \\
(\mathrm{N}=925)\end{array}$ & $\begin{array}{l}\text { Unknown } \\
(\mathrm{N}=11,432)\end{array}$ & $\begin{array}{l}\text { Total } \\
(\mathrm{N}=15,947)\end{array}$ \\
\hline Age at diagnosis & $\mathrm{n}(\%)$ & $\mathrm{n}(\%)$ & $\mathrm{n}(\%)$ & $\mathrm{n}(\%)$ & $\mathrm{n}(\%)$ \\
\hline$<60$ years & $836(35.1)$ & $305(25.3)$ & $58(6.3)$ & $1711(15.0)$ & $2910(18.2)$ \\
\hline $60-69$ years & $1251(52.5)$ & $606(50.3)$ & $166(17.9)$ & $4271(37.4)$ & $6294(39.5)$ \\
\hline $70-79$ years & $279(11.7)$ & $243(20.2)$ & $275(29.7)$ & $3782(33.1)$ & $4579(28.7)$ \\
\hline $80+$ years & $19(0.8)$ & $51(4.2)$ & $426(46.1)$ & $1668(14.6)$ & $2164(13.6)$ \\
\hline \multicolumn{6}{|l|}{ Ethnicity } \\
\hline Māori & $83(3.5)$ & $61(5.1)$ & $80(8.6)$ & $684(6.0)$ & $908(5.7)$ \\
\hline Pacific & $24(1.0)$ & $25(2.1)$ & $46(5.0)$ & $350(3.1)$ & $445(2.8)$ \\
\hline non-Māori/non-Pacific & $2278(95.5)$ & 1119 (92.9) & $799(86.4)$ & $10398(91.0)$ & $14594(91.5)$ \\
\hline
\end{tabular}

*excludes prostate cancer morphology not consistent with adenocarcinoma, men with unknown ethnicity, those diagnosed at death, or domicile listed as "overseas"

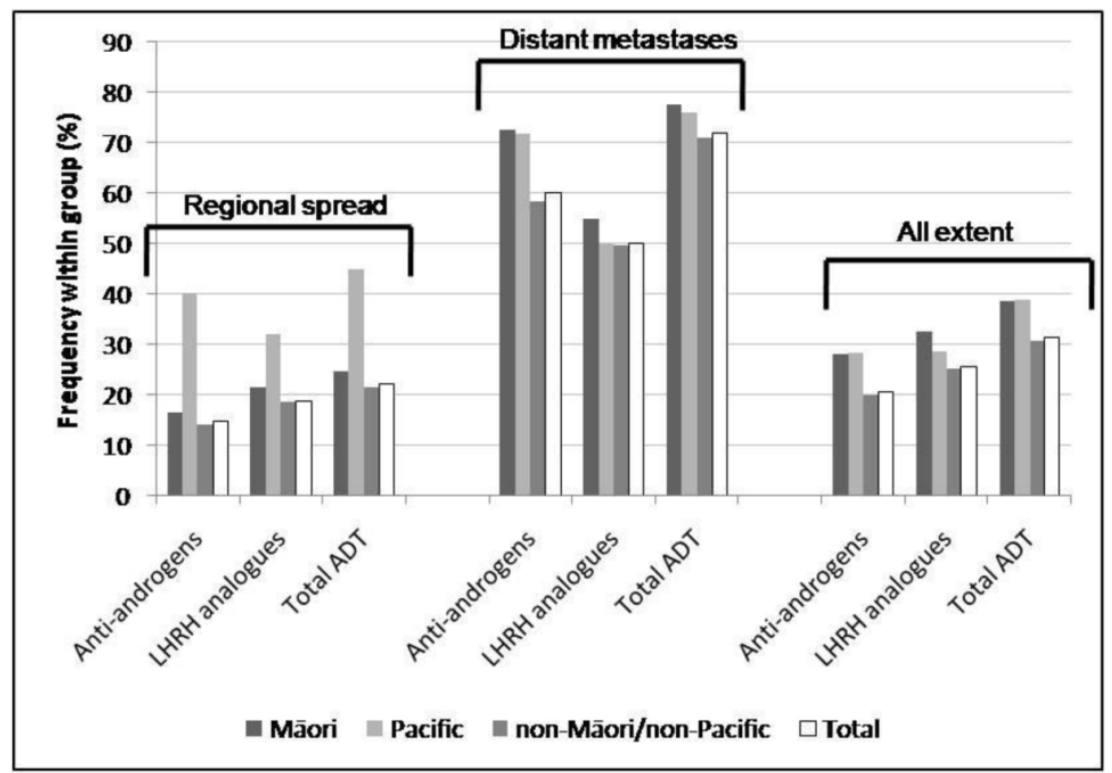

Figure I. Frequency of types of pharmacologic ADT by ethnicity and extent of disease at diagnosis (regional spread, distant metastases and all extent, including localised, regional spread, distant metastases and unknown).Frequency of types of pharmacologic ADT by age group and extent of disease at diagnosis (regional spread, distant metastases and all extent, including localised, regional spread, distant metastases and unknown). 


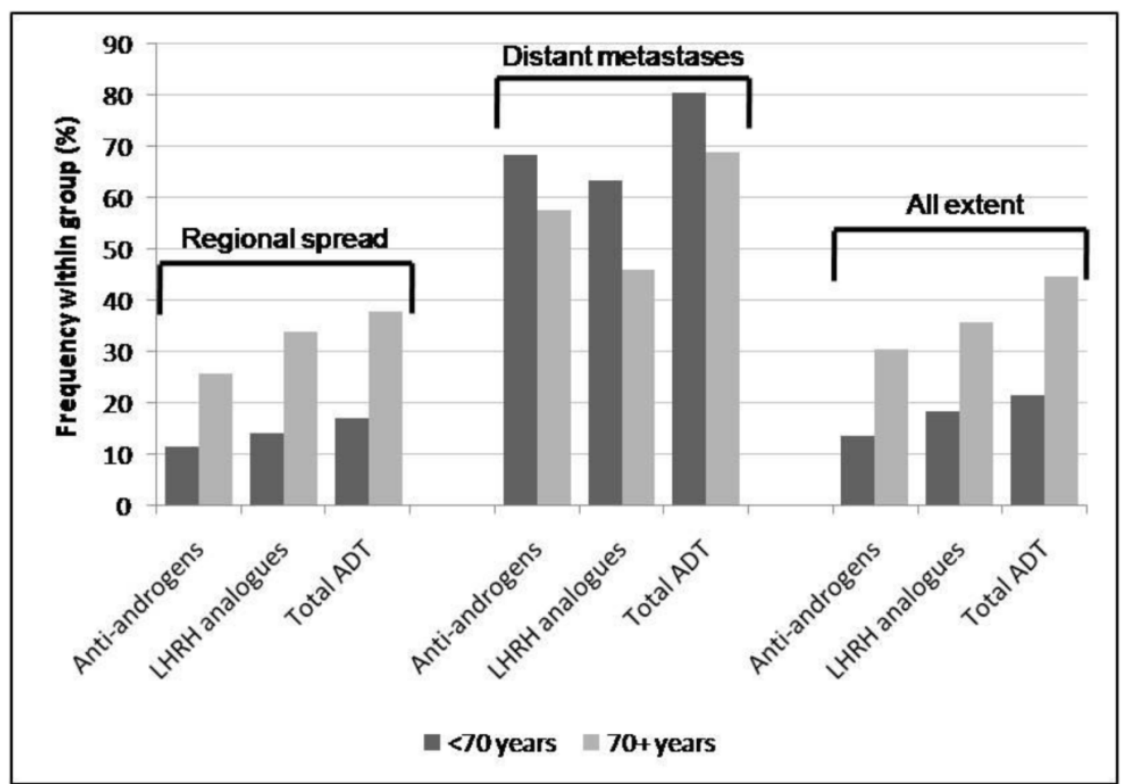

Figure 2. Frequency of types of pharmacologic ADT by age group and extent of disease at diagnosis (regional spread, distant metastases and all extent, including localised, regional spread, distant metastases and unknown).

In patients with metastatic cancer, anti-androgens $(60.1 \%)$ were used more commonly than LHRH analogues $\left(50.1 \% ; X^{2} \mathrm{p}<0.0001\right)$. By contrast, overall (all extents), more patients received LHRH analogues $(25.5 \%)$ than anti-androgens $\left(20.6 \% ; X^{2}\right.$ $\mathrm{p}<0.0001)$ as did patients with regional spread $(18.8 \%$ v. $\left.14.8 \% ; \chi^{2} p=0.008\right)$. Men younger than 70 years overall and specifically those diagnosed with regional prostate cancer were less likely to receive ADT compared with older men $\left(21.3 \%\right.$ v. $44.5 \% ; \chi^{2}$ p $<0.0001$; $17.0 \%$ v. $37.8 \% ; \chi^{2}$ p $<0.0001$, respectively). However, in men diagnosed with metastatic cancer those aged under 70 were more likely to receive ADT than older men $\left(80.4 \%\right.$ v. $\left.69.0 \% ; \chi^{2} p=0.001\right)$.

Overall, ADT was less likely to be dispensed for non-Māori/non-Pacific men than for Māori and Pacific men (30.5\% v. $38.5 \% ; \chi^{2} p<0.0001$, and v. $38.9 \%$; $\chi^{2}$ $\mathrm{p}<0.0001$, respectively). In men with regional disease, Pacific men were more likely to receive ADT compared to non-Māori/non-Pacific men $(44.0 \%$ v. $21.4 \%$; Fisher exact test $\mathrm{p}=0.01)$ and they were also more likely to receive anti-androgens than non-Māori/ non-Pacific and Māori men $(40.0 \%$ v. $14.1 \%$; Fisher exact test $p=0.002$, and v. $16.4 \%$; Fisher exact test $\mathrm{p}=0.03$, respectively). In men with metastatic prostate cancer, Māori men were more likely to receive anti-androgens than non-Māori/non-Pacific men (72.5\% v. $58.2 \%$; Fisher exact test $\mathrm{p}=0.02$ ).

Similarly to anti-androgens and LHRH analogues, orchidectomy can be used to achieve reduction of testosterone levels and thus reduce prostate cancer growth. ${ }^{5}$ In our sample, $3.3 \%$ of patients (165 out of 4968 who were prescribed anti-androgens or LHRH analogues) underwent orchidectomy within the first year after initial diagnosis. The majority of these men $(77.6 \%)$ received either anti-androgens or LHRH analogues but not both in that year. In addition, there were 202 men who underwent orchidectomy but did not receive pharmacologic ADT $(1.8 \%$ of men with prostate cancer not on pharmacologic ADT) in the first year post-diagnosis. Since our further analyses focus on men with advanced (regional spread or metastatic) prostate cancer, Table 2 shows distribution of orchidectomy by age, ethnicity, and pharmacologic ADT use separately for all patients and for those with advanced cancer.

Men older than 70 years with advanced cancer were treated more commonly by orchidectomy only $(10.0 \%$ v. $1.8 \%$; Fisher exact test $\mathrm{p}<0.0001)$, and they were also more likely to undergo orchidectomy overall compared with men younger than $70(7.8 \%$ v. 3.2\%; Fisher exact test $\mathrm{p}<0.0001)$. Māori men with any extent were more likely to be treated by orchidectomy compared to non-Māori/non-Pacific men $\left(3.4 \%\right.$ v. $2.2 \%$; $\chi^{2}$ $\mathrm{p}<0.0001)$.

In order to assess the use of ADT from the clinical point of view, patients with advanced cancer were categorised into three groups, i.e. those who received anti-androgens only, those who received LHRH analogues only and those who received both anti-androgens and LHRH analogues within the first year post diagnosis.

In men with advanced cancer, $53.2 \%$ (out of all men on ADT) received both anti-androgens and LHRH analogues within the first year post-diagnosis, followed by those who received anti-androgens only $(25.8 \%)$ and those who received LHRH analogues only $(21.0 \%)$. Table 3 shows the distribution of an- 
ti-androgens and LHRH analogues use individually and in combination in men with advanced disease.

A significantly larger proportion of men older than 70 years at diagnosis received anti-androgens only compared with men younger than $70(29.4 \% \mathrm{v}$. 19.4\%; Fisher exact test $\mathrm{p}=0.001$ ), while a significantly larger proportion of non-Māori/non-Pacific men received LHRH analogues only compared with Māori and Pacific men $(22.7 \%$ v. $11.7 \%$; Fisher exact test $p=0.03$, and v. $6.5 \%$; Fisher exact test $p=0.009$, respectively).
Multiple logistic regression models were used to assess the effect of age at diagnosis, ethnicity, year of diagnosis, and orchidectomy on the use of ADT (anti-androgens and LHRH analogues alone or combined) in men with advanced cancer at diagnosis. Six different models were built: Model I included age only; Model II age and ethnicity; Model III age, ethnicity and year of diagnosis; Model IV age and orchidectomy; Model V age, ethnicity and orchidectomy; and Model VI included age, ethnicity, year of diagnosis and orchidectomy (Table 4).

Table 2. Frequency of orchidectomy by age, ethnicity and extent of cancer at diagnosis.

\begin{tabular}{|c|c|c|c|c|c|c|}
\hline \multirow{2}{*}{$\begin{array}{l}\text { Extent at diagnosis } \\
\text { Therapy }\end{array}$} & \multicolumn{3}{|c|}{ Advanced cancer } & \multicolumn{3}{|c|}{ All extent } \\
\hline & $\begin{array}{l}\text { Orchidectomy } \\
\text { plus ADT }\end{array}$ & $\begin{array}{l}\text { Orchidectomy } \\
\text { only }\end{array}$ & $\begin{array}{l}\text { Orchidectomy } \\
\text { total }\end{array}$ & $\begin{array}{l}\text { Orchidectomy } \\
\text { plus ADT }\end{array}$ & Orchidectomy only & $\begin{array}{l}\text { Orchidectomy } \\
\text { total }\end{array}$ \\
\hline Age at diagnosis & $\mathrm{n} / \mathrm{N}(\%)$ & $\mathrm{n} / \mathrm{N}(\%)$ & $\mathrm{n} / \mathrm{N}(\%)$ & $\mathrm{n} / \mathrm{N}(\%)$ & $\mathrm{n} / \mathrm{N}(\%)$ & $\mathrm{n} / \mathrm{N}(\%)$ \\
\hline$<70$ years & $\begin{array}{l}22 / 335 \\
(6.6)\end{array}$ & $\begin{array}{l}14 / 800 \\
(1.8)\end{array}$ & $\begin{array}{l}36 / 1135 \\
(3.2)\end{array}$ & $\begin{array}{l}45 / 1964 \\
(2.3)\end{array}$ & $\begin{array}{l}35 / 7240 \\
(0.5)\end{array}$ & $\begin{array}{l}80 / 9204 \\
(0.9)\end{array}$ \\
\hline $70+$ years & $\begin{array}{l}38 / 595 \\
(6.4)\end{array}$ & $\begin{array}{l}40 / 400 \\
(10.0)\end{array}$ & $\begin{array}{l}78 / 995 \\
(7.8)\end{array}$ & $120 / 3004(4.0)$ & $167 / 3739(4.5)$ & $287 / 6743(4.3)$ \\
\hline \multicolumn{7}{|l|}{ Ethnicity } \\
\hline Māori & $\begin{array}{l}6 / 77 \\
(7.8)\end{array}$ & $\begin{array}{l}4 / 64 \\
(6.3)\end{array}$ & $\begin{array}{l}10 / 141 \\
(7.1)\end{array}$ & $\begin{array}{l}12 / 350 \\
(3.4)\end{array}$ & $\begin{array}{l}19 / 558 \\
(3.4)\end{array}$ & $\begin{array}{l}31 / 908 \\
(3.4)\end{array}$ \\
\hline Pacific & $\begin{array}{l}3 / 46 \\
(6.5)\end{array}$ & $\begin{array}{l}3 / 25 \\
(12.0)\end{array}$ & $\begin{array}{l}6 / 71 \\
(8.5)\end{array}$ & $\begin{array}{l}6 / 173 \\
(3.5)\end{array}$ & $\begin{array}{l}7 / 272 \\
(2.6)\end{array}$ & $\begin{array}{l}13 / 445 \\
(2.9)\end{array}$ \\
\hline non-Māori/non-Pacific & $\begin{array}{l}51 / 807 \\
(6.3)\end{array}$ & $\begin{array}{l}47 / 1111 \\
(4.2)\end{array}$ & $\begin{array}{l}98 / 1918 \\
(5.1)\end{array}$ & $147 / 4445(3.3)$ & $176 / 10149(1.7)$ & $323 / 14594(2.2)$ \\
\hline Total & $\begin{array}{l}60 / 930 \\
(6.5)\end{array}$ & $\begin{array}{l}54 / 1200 \\
(4.5)\end{array}$ & $\begin{array}{l}114 / 2130 \\
(5.4)\end{array}$ & $165 / 4968(3.3)$ & $202 / 10979(1.8)$ & $367 / 15947(2.3)$ \\
\hline
\end{tabular}

Table 3. Proportion of types of ADT in men with advanced cancer by age and ethnicity.

\begin{tabular}{lllll}
\hline Therapy & $\mathrm{N}$ & $\begin{array}{l}\text { Anti-androgens } \\
\mathrm{n}(\%)\end{array}$ & $\begin{array}{l}\text { LHRH analogues } \\
\mathrm{n}(\%)\end{array}$ & $\begin{array}{l}\text { Anti-androgens plus LHRH analogues } \\
\mathrm{n}(\%)\end{array}$ \\
\hline $\begin{array}{l}\text { Age at diagnosis } \\
<70 \text { years }\end{array}$ & 335 & $65(19.4)$ & $79(23.6)$ & $191(57.0)$ \\
$\begin{array}{l}70+\text { years } \\
\text { Ethnicity }\end{array}$ & 595 & $175(29.4)$ & $116(19.5)$ & $304(51.1)$ \\
$\begin{array}{l}\text { Māori } \\
\text { Pacific }\end{array}$ & 77 & $20(26.0)$ & $9(11.7)$ & $48(62.3)$ \\
$\begin{array}{l}\text { non-Māori/non-Pacific } \\
\text { Total }\end{array}$ & 46 & $15(32.6)$ & $3(6.5)$ & $28(60.9)$ \\
\hline
\end{tabular}

Table 4. Odds ratio of receiving ADT based on logistic regression models adjusted for age, ethnicity, year of diagnosis and orchidectomy.

\begin{tabular}{|c|c|c|c|c|}
\hline & & \multirow{3}{*}{$\begin{array}{l}\text { Age (continuous) } \\
\text { OR }(95 \% \mathrm{CI})\end{array}$} & \multirow{2}{*}{\multicolumn{2}{|c|}{$\begin{array}{l}\text { Ethnicity OR }(95 \% \text { CI) } \\
\text { Non-Māori/non-Pacific Reference (1.00) }\end{array}$}} \\
\hline & & & & \\
\hline & & & Māori & Pacific \\
\hline Model I & Age & $\begin{array}{l}1.06 \\
(1.05,1.07)\end{array}$ & & \\
\hline Model II & Age \& ethnicity & $\begin{array}{l}1.07 \\
(1.06,1.08)\end{array}$ & $\begin{array}{l}2.06 \\
(1.43,2.94)\end{array}$ & $\begin{array}{l}3.12 \\
(1.86,5.24)\end{array}$ \\
\hline Model III & Age, ethnicity \& year of diagnosis ${ }^{a}$ & $\begin{array}{l}1.07 \\
(1.06,1.08)\end{array}$ & $\begin{array}{l}2.06 \\
(1.44,2.95)\end{array}$ & $\begin{array}{l}3.15 \\
(1.87,5.28)\end{array}$ \\
\hline Model IV & Age \& orchidectomy ${ }^{a}$ & $\begin{array}{l}1.06 \\
(1.05,1.07)\end{array}$ & & \\
\hline Model V & Age, ethnicity \& orchidectomy ${ }^{a}$ & $\begin{array}{l}1.06 \\
(1.06,1.08)\end{array}$ & $\begin{array}{l}2.05 \\
(1.43,2.94)\end{array}$ & $\begin{array}{l}3.11 \\
(1.85,5.22)\end{array}$ \\
\hline Model VI & Age, ethnicity, year of diagnosis \& orchidectomy & $\begin{array}{l}1.06 \\
(1.06,1.08)\end{array}$ & $\begin{array}{l}2.05 \\
(1.43,2.94)\end{array}$ & $\begin{array}{l}3.14 \\
(1.87,5.27)\end{array}$ \\
\hline
\end{tabular}

ayear of diagnosis and orchidectomy showed a non-significant slope $(<0.05)$ 
In all models, age was a contributing factor, with older men with advanced cancer being more likely to receive ADT. Māori and Pacific men (compared with non-Māori/non-Pacific men) were approximately 2.1and 3.1-fold more likely to receive pharmacologic ADT when adjusting for age and combinations of age, year of diagnosis and orchidectomy. However, year of diagnosis and orchidectomy in the same year did not seem to pose as confounders and did not significantly contribute to the models.

\section{Discussion}

The aim of this study was to assess the frequency of use of ADT and chemotherapeutic agents for NZ men in the first year after cancer diagnosis, particularly for metastatic patients for whom ADT should be prescribed immediately. ${ }^{9}$ Therefore, we have not followed up the cohort for a longer period of time.

Seventy two percent of men recorded as having metastatic disease at diagnosis received pharmacologic ADT (anti-androgens and/or LHRH analogues). Whilst a small number of men with prostate cancer had an orchidectomy $(2 \%)$, it seems that a quarter of men with advanced prostate cancer did not receive hormonal treatment. Since management guidelines for locally advanced and particularly metastatic prostate cancer clearly include use of androgen deprivation therapy as part of the treatment pathway, ${ }^{5,10}$, there is a need for improvement in this area in New Zealand. In comparison, in the USA 95\% patients diagnosed between 1994 and 2002 with stage IV disease received either surgical or pharmacologic ADT, while $16 \%$ received chemotherapy. ${ }^{11}$

In our sample, chemotherapeutic agents were used very rarely in the first year post-diagnosis. Only five men received docetaxel and 11 men received doxorubicin. Some of the chemotherapeutic agents, such as docetaxel were first subsidised in 2011, so they would not appear in the Pharmaceutical Collection previously. There seems to be a greater potential for the use of these agents and newer treatments in men with hormone-refractory advanced prostate cancer. ${ }^{5}$

Older men with metastatic disease in particular were less likely to receive pharmacologic ADT. A larger proportion of men older than 70 years at diagnosis received anti-androgens only compared to men younger than 70 . Older men were also more likely to be treated with orchidectomy only.

Contrary to our expectations Māori and Pacific men were more likely to receive ADT than non-Māori/non-Pacific men. However, there were additional differences in the management of Māori patients. Māori men were more likely to be treated with orchidectomy, while they were less likely to re- ceive LHRH analogues when compared with non-Māori/non-Pacific men. The dispensing of pharmacologic ADT and use of orchidectomy for reduction of testosterone levels in advanced prostate cancer was influenced mainly by patients' age and ethnicity.

Men with advanced prostate cancer were more likely prescribed both anti-androgens and LHRH analogues in the first year as opposed to anti-androgens or LHRH analogues alone. Data from other countries showed that physician preference has an important influence on the use of $\mathrm{ADT}^{4}$, as do the presence of subsidies ${ }^{12}$, patient's age and tumour grade at diagnosis. ${ }^{13}$ Thus the solution to improved dispensing is likely to involve a greater understanding of the barriers to prescribing from the physicians' perspective but also of patients' views on ADT use.

The strength of this study is that we used data linkage to assess use of ADT nationally. Men registered with prostate cancer in the New Zealand Cancer Registry were identified and this information was linked to the national dataset of pharmaceutical dispensings as well as to the National Minimum Dataset to ensure that the use of orchidectomy did not introduce a bias into our analysis. This allowed us to undertake a large-scale pharmaco-epidemiological study on the dispensing of ADT and chemotherapeutic agents, which is quite unique internationally.

Studies from other countries investigated the use of ADT in certain patient groups, such as Medicare beneficiaries or patients visiting specialist services, but to our knowledge none were population-based.11,14-18 In addition, several of the most recent studies were restricted to prostate cancer patients with localised disease. These studies highlighted the benefits of using ADT as primary or adjuvant therapy, particularly in high-risk patients. ${ }^{14-17}$

The main weakness of our study is that $72 \%$ of men registered with prostate cancer had the extent of disease recorded as "unknown". This may have reduced the power of the study and introduced bias if men with advanced disease with known extent in the NZCR were treated differently than men with advanced disease at diagnosis whose extent was recorded as "unknown". Prostate cancer is similar to bladder and liver cancer with respect to the low recording of extent at diagnosis. Although the proportion of incident prostate cancer cases with known extent at diagnosis slightly improved from $25.7 \%$ to 28.1\% between 2006 and 2010, for further research into prostate cancer on national level it will be essential to at least achieve proportions of known extent similar to colorectal and breast cancer, where more than $80 \%$ of cases have known extent recorded. ${ }^{6}$ The New Zealand 
Cancer Control Council is currently reviewing the reporting of all cancers in an effort to improve the availability of data in the NZCR, including extent at diagnosis. ${ }^{19}$

Another weakness may be potentially incomplete information linkage either due to incomplete coverage of NHI numbers or deficiencies in reporting. However, the use of NHI numbers across the country was on average $95 \%$ during the study period, and more than $95 \%$ of all prescriptions recorded in the Pharmaceutical Collection have had an NHI attached. In addition, the reporting of pharmaceutical cancer data by district health boards was voluntary until July 2008, which may have affected data linkage in the first years of the study. However, the frequency of ADT use in the first year after diagnosis was $70.2 \%$ for men diagnosed with distant metastases in 2006-2007 and $70.9 \%$ for those diagnosed in 2009-2010. Therefore, even if changes in data recording within this period might have had an impact, it does not appear to be substantial.

This audit showed that there is a clear under-utilisation of ADT and particularly chemotherapeutic agents in NZ men with advanced prostate cancer. Particularly in men with distant metastases there is little doubt that immediate androgen deprivation therapy improves outcomes. ${ }^{9}$

\section{Acknowledgement}

The study was sponsored by UniServices Auckland and funded through a research grant with Janssen Pharmaceuticals.

\section{Competing interests}

RL received a fee for attending an advisory committee meeting from Janssen Pharmaceuticals. PF has been paid honoraria for acting in the capacity of medical oncology consultant advisor to Janssen Pharmaceuticals with regards to treatment of prostate cancer in New Zealand. Other co-authors have declared no competing interests.

\section{References}

1. Ministry of Health. New Registrations and Deaths 2006: Revised edition. Wellington: Ministry of Health; 2010.

2. Johansson JE, Holmberg L, Johansson S, et al. Fifteen-year survival in prostate cancer. A prospective, population-based study in Sweden. JAMA 1997; 277: 467-71.

3. Obertová Z, Hodgson F, Holmes M, et al. Characteristics of men diagnosed with prostate cancer in New Zealand general practice. NZ Med J 2013; 126 (1387).

4. Shahinian VB, Kuo YF, Freeman JL, Goodwin JS. Determinants of androgen deprivation therapy use for prostate cancer: role of the urologist. J Natl Cancer Inst 2006; 98: 839-45.

5. National Institute for Health and Clinical Excellence (NICE). Prostate cancer diagnosis and treatment. Clinical guideline 58. London: NICE; 2008.

6. Robson B, Harris R (eds). Hauora: Māori standards of health IV. A study of the years 2000-2005. Wellington: Te Ropu Rangahau Hauora a Eru Pomare; 2007.

7. Obertová Z, Scott N, Brown C, et al. Survival disparities between Māori and non-Māori men with non-localised prostate cancer in New Zealand. BJU Int Suppl. 2013; 112 (1): 14.
8. Hussain S, Gunnell D, Donovan J, et al. Secular trends in prostate cancer mortality, incidence and treatment: England and Wales, 1975-2004. BJU Int 2008; 101: 547-55.

9. Pagliarulo V, Bracarda S, Eisenberger MA, et al. Contemporary role of androgen deprivation therapy for prostate cancer. Eur Urol 2012; 61: 11-25.

10. Australian Cancer Network Management of Metastatic Prostate Cancer Working Party. Clinical Practice Guidelines for the Management of Locally Advanced and Metastatic Prostate Cancer. Sydney: Cancer Council Australia and Australian Cancer Network; 2010.

11. Onukwugha E, Mullins CD, Hsu VD, et al. Effect of Urologists and Medical Oncologists on Treatment of Elderly Men With Stage IV Prostate Cancer. Urology 2011; 77: 1088-96.

12. Morrison BF, Aiken WD, Reid ME. Impact of the National Health Fund policy on hormone treatment for prostate cancer in Jamaica. Rev Panam Salud Publica 2011; 29: 404-8.

13. Grundmark B, Garmo H, Zethelius B, et al. Anti-androgen prescribing patterns, patient treatment adherence and influencing factors; results from the nationwide PCBaSe Sweden. Eur J Clin Pharmacol 2012; 68: 1619-30.

14. Akaza H. Future prospects for luteinizing hormone-releasing hormone analogues in prostate cancer treatment. Pharmacology 2010; 85: 110-20.

15. Akaza H, Hinotsu S, Cooperberg MR, et al. Sixth joint meeting of J-CaP and CaPSURE - A multinational perspective on prostate cancer management and patient outcomes. Jpn J Clin Oncol 2013; 43: 756-66.

16. Cooperberg MR, Grossfeld GD, Lubeck DP, Carroll PR. National practice patterns and time trends in androgen ablation for localized prostate cancer. J Natl Cancer Inst 2003; 95: 981-9.

17. Kuykendal AR, Hendrix LH, Salloum RG, et al. Guideline-discordant androgen deprivation therapy in localized prostate cancer: patterns of use in the medicare population and cost implications. Ann Oncol 2013; 24: 1338-43.

18. Dinan MA, Robinson TJ, Zagar TM, et al. Changes in initial treatment for prostate cancer among Medicare beneficiaries, 1999-2007. Int J Radiation Oncol Biol Phys 2012; 22: 781-6.

19. Ministry of Health. Treatment: Report of the Treatment Expert Working Group to the New Zealand Cancer Control Steering Group. Wellington: Ministry of Health; 2003. 